\title{
Assessment of Experimental Models for Obtaining Adipose-Derived Mesenchymal Stem Cells
}

\author{
Ângelo César D'Urso Panerari ${ }^{1,2,3,4}$ \\ https://orcid.org/0000-0002-1524-8186 \\ Isis Sousa Oliveira ${ }^{5}$ \\ https://orcid.org/0000-0002-3635-7867 \\ Giovani Marino Favero ${ }^{*}$ \\ https://orcid.org/0000-0002-1946-3262 \\ Henrique Olavo de Olival Costa ${ }^{1}$
https://orcid.org/0000-0002-1914-2493
}

${ }^{1}$ Department of Otorhinolaryngology of the Santa Casa de São Paulo and at the Institute of Advanced Science and Otorhinolaryngology - ICAO, São Paulo, Brazil. ${ }^{2}$ Department of Medicine, UNICESUMAR, Paraná, Brazil. ${ }^{3}$ Department of Medicine, Faculdades Ingá, Paraná, Brazil. "Department of Medicine, State University of Maringá, Paraná, Brazil. ${ }^{5}$ Federal University of ABC. ${ }^{6}$ Laboratory of Integrated Pathophysiology of the Immune Response, State University of Ponta Grossa, Paraná, Brazil

Received: 2019.05.10; Accepted: 2020.02.10.

${ }^{*}$ Corresponding author: Prof. Dr. Giovani Marino Favero; Department of General Biology, Ponta Grossa State University, 84030-900, Ponta Grossa, Parana, Brazil. Telefax: + 55-42-3220-3002. E-mail: gmfavero@uepg.br

\section{HIGHLIGHTS}

- Experimental models to retrieval mesenchymal stem cell from adipose tissue.

- Rat Inguinal region mesenchymal stem cells.

\begin{abstract}
Creating experimental models for obtaining stem cells from adipose tissue is necessary to elucidate their peculiar features. Objective: This study proposed a reliable reproducible and consistent experimental model for obtaining mesenchymal stem cells from adipose tissue. Material and Method: Lines of New Zealand rabbits, Wistar rats and CaviaPorcellus guinea pigs (4 animals per species) were used. Fatty tissue mesenchymal stem cells were removed from dorsal, epididymal and inguinal regions. Percentage viable cells and percentage cells expanded and submitted to chondrogenic differentiation were compared by animal species and collection site. Results: Chondrogenic differentiation occurred in a similar manner across all samples, independently of animal species or collection site. Among samples assessed, the inguinal region of rats yielded the highest percentage of viable and expanded cells. Conclusion: A reliable, reproducible and consistent model for obtaining mesenchymal stem cells was produced. Of the several variables analysed, the best results were obtained from the inguinal region of the rat.
\end{abstract}

Keywords: adipose tissue; mesenchymal stem cell; transplantation. 


\section{INTRODUCTION}

Regenerative Medicine is a field of science yielding major advances in medicine. The ideal candidates for regenerative medicine are multi-potent mesenchymal stem cells (MSC) which, by definition, have high potential for self-regeneration, for forming undifferentiated cells and for differentiating into cells from a wide variety of lineages [1]. Isolation of these cells after collection from different tissue sites, coupled with the recent development of somatic cell nuclear transfer, has enabled the acquisition of sufficiently high yields of cells for therapeutic use in an array of injuries, diseases and autologous transplants [2].

The majority of research work conducted on adult MSC has used bone marrow as a tissue source. However, the use of this site has a number of inherent drawbacks: donor discomfort and risk during collection as well as a low yield of MSC compared to other tissue sources [3]. Given these disadvantages, investigations have been undertaken to explore the potential for producing MSC sourced from other tissues. In this regard, adipose tissue has shown promise given its ease of collection, low morbidity during extraction, high volume of available donor tissue, and substantial yield of MSC in its stroma capable of undergoing proliferation and differentiation as compared to bone marrow [4].

However, few studies comparing experimental models and collection sites have been conducted to date. The reports in the literature describe different ways of obtaining adipose-derived MSC but fail to provide in-depth descriptions on the methods used and do not compare different methods. There is currently insufficient evidence to run reliable animal experiments to produce adipose-derived MSC.

Therefore, the present study proposes to compare the animal models available for obtaining MSC from adipose tissue.

\section{MATERIAL AND METHODS}

The study was carried out at the animal house of the Institute of Advanced Sciences in Ear Nose and Throat (ICAO), in accordance with the regulations of Brazilian Federal Law and pursuant to the ethical principles in experimentation set forth in the Brazilian Code of Experimentation in animals (COBEA). The process of cellular analysis, expansion and differentiation was carried out at the Institute for Stem Cell Research (IPCTRON).

Male animals of different species selected from lines of New Zealand rabbits, Wistar rats and CaviaPorcellus guinea pigs were studied. A total of 12 animals (4 of each species) selected according to weight and age, were used in this study

For each species, three young adult animals of normal weight, together with a fourth animal considered old and overweight, were selected.

The animals were distributed according to cell extraction site. Adipose tissue was removed from the dorsal, epididymal and inguinal regions. Four animals were used for each collection site.

The surgical procedures were performed under general intramuscular anesthesia using xylazine 10 $\mathrm{mg} / \mathrm{kg}$ (xylazinechlorohydrate 2\%) and $40 \mathrm{mg} / \mathrm{kg}$. ketamine (Francotar). Independent collection from each respective region was carried out after trichotomy and local application of antiseptic ethanol (70\%). Animals were submitted to euthanasia immediately after the surgical procedure, while still anesthetized, by intracardiac injection of $10 \% \mathrm{KCL}$ Adipose tissue was collected from dorsal, inguinal and epididymal regions of the animals and specimens immediately sent to the laboratory adjacent to the surgical center. At the laboratory, cellular isolation, cultivation and counting were carried out. A $0.8 \mathrm{~mL}$ volume of material was removed from each animal, regardless of species or collection site. Assessment parameters included percentage of viable cells and percentage of cells expanded and submitted to differentiation (Figure 1).

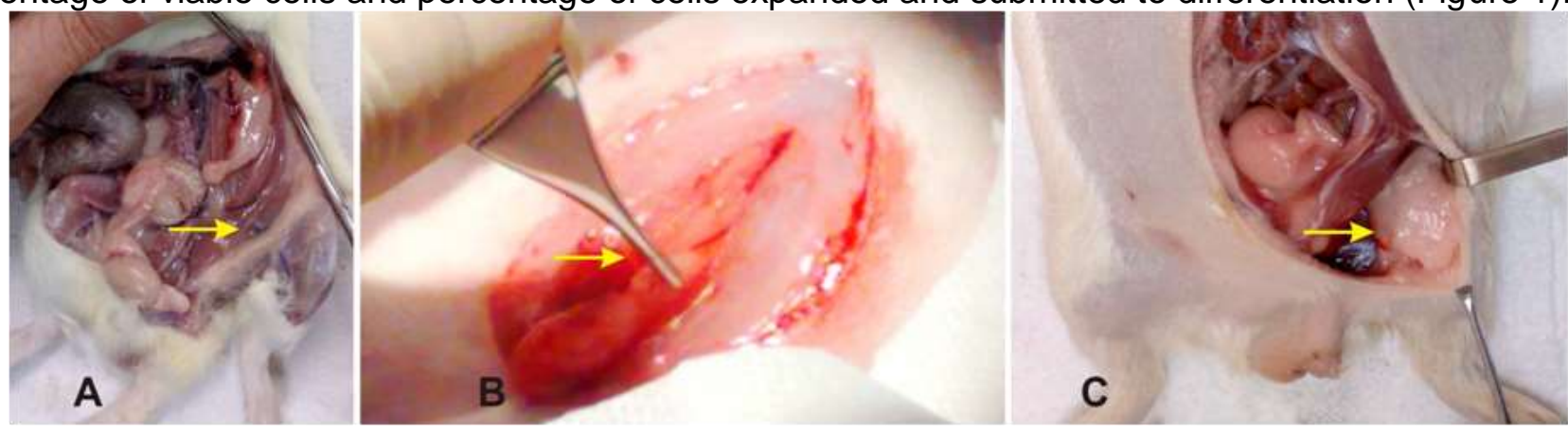

Figure 1. Adipose tissue from dorsal region of rat $(A)$, rabbit $(B)$ and guinea pig $(C)$ (arrow) 


\section{Stem cell isolation, cultivation and counting}

After collection, the tissue specimens were fragmented and placed on a Petri plate containing sterile phosphate-buffered saline (PBS) with $1 \%$ penicillin and streptomycin (PE).Tissue fragments were then rinsed in 1\% PBS solution (PE). Cells were subjected to a digestion process using HyQTase enzyme, a Synthetic Trypsin. The solution obtained from enzymatic digestion was centrifuged at $2000 \mathrm{rpm}$ for 10 minutes. Supernatant was discarded and cell pellets resuspended in $2 \%$ PBS (PE) for washing. Cell counting was performed on a Newbauer Chamber together with the vital stain selected (Trypan Blue). After counting, cells were submitted to the cellular cultivation process. Stem cells obtained were then seeded in $25 \mathrm{~mL}$ culture bottles at $2.5 \times 10^{(5)}$ cells per plate and cultivated in DMEM medium containing $10 \%$ fetal bovine serum, supplemented with $62 \mu \mathrm{L} / \mathrm{mL}$ penicillin and $50 \mu \mathrm{L} / \mathrm{mL}$ streptomycin. After the first 48 hours, the medium was changed every two days. Medium was changed until the cells had reached approximately $70 \%$ confluence, at which point cells were submitted to trypsinization and then underwent the second expansion passage (Figure 2).
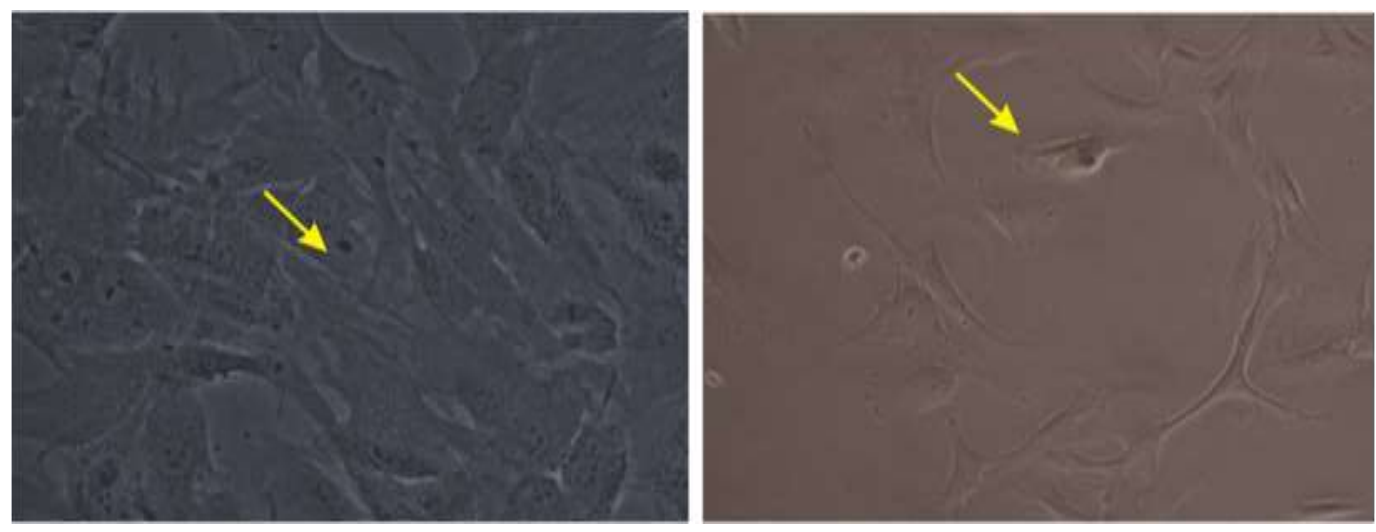

Figure 2. Photomicrography revealing cellular differentiation in chondrocytes (arrow)

Cells were submitted to the differentiation process in order to confirm manipulation of MSC and to verify whether expanded cells displayed chondrogenic potential. Cellular pellets were cultivated at $37^{\circ} \mathrm{C}$ with $5 \% \mathrm{CO}^{2}$ in a high glucose DMEM medium supplemented with $10 \mathrm{ng} / \mathrm{mL}$ transforming growth factor (TGF- 33 ), 10(-7)M dexamethasone (decadron), $50 \mu \mathrm{L} / \mathrm{mL}$ ascorbate-2 phosphate, $40 \mu \mathrm{L}$ proline, $100 \mu \mathrm{L} / \mathrm{mL}$ pyruvate, $50 \mathrm{mg} / \mathrm{mL}$ ITS + Premix (Becton Dickinson; $6.25 \mu \mathrm{L}$ insulin, $6.25 \mu \mathrm{L}$ transferrin, $6.25 \mathrm{ng} / \mathrm{mL}$ selenious acid, $1.25 \mathrm{mg} / \mathrm{mL} \mathrm{BSA}$, and $5.35 \mathrm{mg} / \mathrm{mL}$ linoleic acid), with the addition of $500 \mathrm{ng} / \mathrm{mL}$ of bone morphogenic protein-6 (BMP-6). The confirmatory analysis of differentiation of MSC into chondrocytes was based on cellular morphology using Alcian Blue staining at low pH which stains the sulfated proteoglycans characteristic of cartilage matrix.

\section{Statistical Analysis}

The ANOVA (analysis of variance) test was used to assess the probability of significant differences among the samples at a significant level of $p<0.05$. The Prisma software program was employed for statistical analysis.

\section{RESULTS}

At the initial cultures, a significant number of rounded cells, non-adherent to the plastic, were detected. These cells were removed after 48 hours at the first change of supernatant medium. Changes in cellular morphology and the acquirement of fibroblast form occurred progressively as cells expanded in plastic cultures. Chondrogenic differentiation proved similar, independent of tissue collection site or animal species studied (Figure 3). 


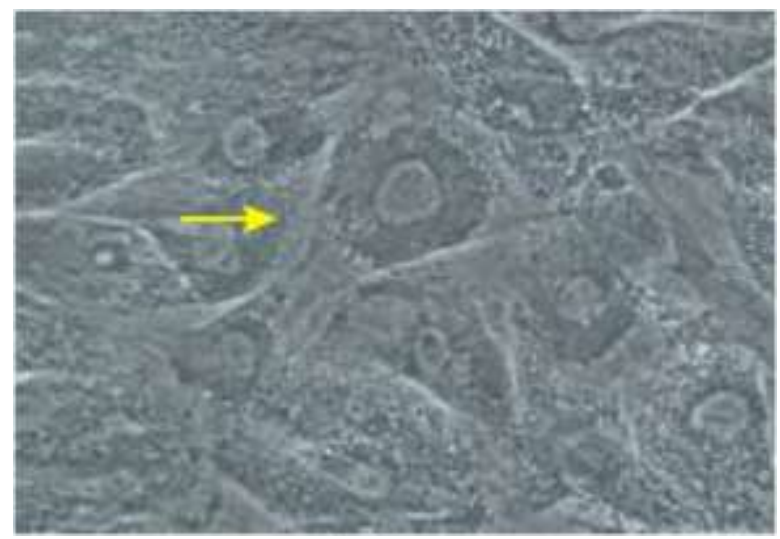

Figure 3. Mesenchymal stem cells from dorsal region at first passage (A) and second passage (B) (400x) (arrow)

During the cellular expansion process, contamination of the cells from four rabbits was detected. Two of these cases involved cell samples taken from the inguinal region and two from the epididymal region. Three contaminations occurred between first and second expansion passages, while one contamination took place between initial counting and the first expansion passage.

After analyzing results of the cell counts for the initial collection and the two expansion processes, an assessment comparing number of cells obtained by site and animal species and respective rates of cell growth, was carried out. The rat was the animal species found to yield the largest number of cells, regardless of collection site or analysis time (Figure 4).
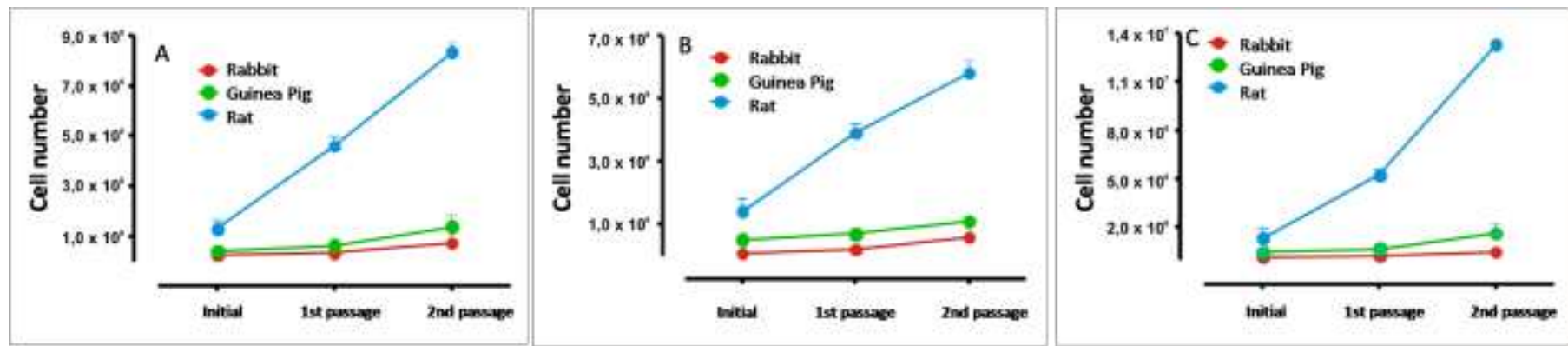

Figure 4. Cellular count and growth for dorsal (A), epididymis (B) and inguinal (C) regions at collection, first and second passages

A further assessment was done comparing initial progenitor cell count and growth rate in two expansion processes based on different collection sites in the same animal species. In rabbits, the three collection sites had similar cell counts and growth rates, while the dorsal region was found to have the greatest number of cells compared with all analyses, although this difference only reached statistical significance for the second passage and the inguinal region.

The comparative assessment of different collection sites of the guinea pig showed similar results across all collection sites on initial counting and for the expansion processes, revealing no statistical differences. The only exception was found for the comparison of cell count on the second passage between epididymal and inguinal regions, which revealed significantly greater cell growth in the inguinal region due to a higher growth rate between first and second passages for the region. Initial cell counts for rats had a statistically similar number of cells across all collection sites. A lower cell count was observed on the first expansion passage for the epididymal region compared to other regions, due to lower growth rates, a finding which persisted on the second expansion passage. The dorsal region had a similar cell count to the inguinal region on the first passage, but a lower cell count on the second expansion due to a lower expansion rate between first and second expansion passages, whereas the inguinal region had a greater number of cells during this phase compared to all the other regions (Figure 5). 

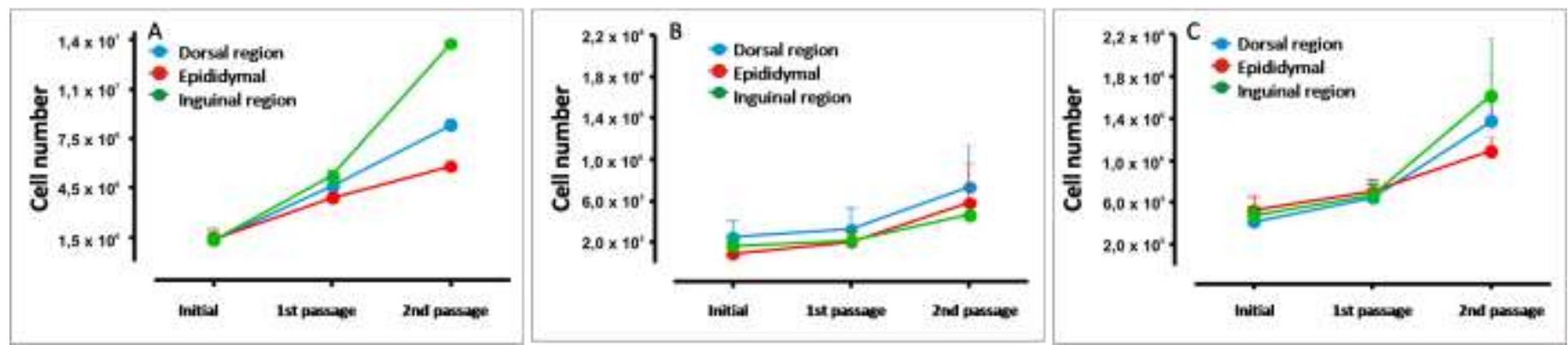

Figure 5. Comparison of cellular count and growth by collection site in rabbits (A), guinea pigs (B) and rats (C), at initial collection, first and second passages

\section{DISCUSSION}

The present study in rats, guinea pigs and rabbits, found rats to be the species with the highest initial cell count per $\mathrm{mm}^{3}$ and the greatest proliferation rate for the two expansion processes. These differences reached statistical significance. However, these results should be interpreted with caution since several studies have shown cell counts among different animal species to converge over time $[5,6]$.

Previous studies comparing different methods of obtaining mesenchymal stem cells from adipose tissue by collection site and species have used an $\mathrm{N}$ of between five and 10 animals $[5,7,8,9]$. The sample size of the present study was deemed adequate ( $\mathrm{N}=12$, 4 per group) for a pilot study investigating the quantity of MSC collected, and their capacity for expansion and differentiation. The fourth animal in each group was considered old and obese and, despite low statistical representativeness, was included to provide a preliminary assessment as to whether age or weight influence the variables studied. The results however, failed to confirm any effect of age or weight.

A range of tissue sites has been used in studies comparing proliferation and differentiation of MSC for a variety of collection sites [5-8]. Some studies also compared brown and white adipose tissues [6,9].

The results of the present study showed a statistically similar initial cell count across the tissue collection sites, independently of animal species. During the expansion process, a greater proliferation rate was observed for cells of adipose tissue from the subcutaneous (inguinal) region, compared to cells from visceral (epididymis) white fat or subcutaneous brown fat (dorsal) in both rat and guinea pig animal species. In rabbits, the dorsal region (brown subcutaneous adipose tissue) was associated with a higher initial cell count and expansion rate, although this difference was not statistically significant among the sites studied but reached statistical significance on the second passage and only when compared with the inguinal region. These findings are consistent with the results obtained other authors $[7,8,9]$ but differ to those reported by Arrigoni and coauthors [6], in studies on rats which showed a higher number of cells at initial count in brown visceral adipose tissue from the Peri renal area, compared with cells in white subcutaneous fat from the inguinal region. These disparities demonstrate the complexity of adipose tissue which comprises different cellular types and behavior depending on collection site. Further studies are needed to elucidate the mechanisms involved

A study in 2011 [8] collected 6.29 grams of adipose tissue from the cervical region and 4.82 grams of visceral fat. Other work [5] removed small amounts of fatty tissue from the patellar region and noted that the amount collected had no effect on cellular count or proliferation. This approach was adopted in the present study, where the same amount was collected $(0.8 \mathrm{~mL})$ from all sites studied.

Studies on adipose tissue tend to use three main methods of specimen collection: lipectomy, liposuction with the tumescent technique, and ultrasound assisted liposuction. In the present study, lipectomy was the surgical approach chosen for removing adipose tissue, since the majority of experimental studies collecting adipose tissue-derived MSC have used lipectomy as the surgical technique [5-9].

Cellswere submitted to the differentiation process at the third expansion passage (cell density of $3.2 \mathrm{x}$ $10^{5}$ to8.5 $\times 10^{6}$ cells per $100 \mathrm{~mm}$ ) in order to compare proliferation potential and confirm whether expanded cells displayed chondrogenic potential. Previous studies have used between two and four expansion passages and a cell density of $5 \times 10^{3}$ to $7 \times 10^{6}$, prior to employing the cells for the purposes of the study, which ranged from differentiation into other tissues to applying them clinically[1,6-11].

Here, higher initial cell counts and yields in the expansion process were found for MSC derived from adipose tissue of rats and the same differentiation capacity was noted irrespective of animal species. 
However, this study performed only two expansion processes, whereas some studies in the literature $[5,6]$ submitted MSC to various expansion processes, observing different cellular duplication and differentiation behaviors with greater multiplications. These findings suggest that our study may have produced different results if a greater number of expansions had been performed. This is an important factor, since in the context of using these cells in vivo it is crucial to ascertain whether these cells will maintain their capacity for proliferation over time and for differentiation into other tissues.

With regard to specific markers, no specific marker has been established for MSC, where the majority of studies involving markers have been carried out on human MSC. Few such studies have been conducted in rodents, although it is clear that markers change according to species [12].

Concerning differentiation of MSC, the majority of studies have promoted differentiation in several tissue types in a bid to confirm the manipulation of MSC $[1,8,9,13]$. In the present study however, chondrogenesis was chosen because the Ear, Nose and Throat as well as Head Surgery specialties often require cartilage replacement, akin to other studies which differentiated MSC into chondrocytes [4,14].

The analysis of cartilage differentiation can be approached in several ways. It can be performed by staining with Alcian Blue, or by Sarafin-O immunohistochemistry for detecting type II collagen, or by histology using histological grading scores to analyse the cartilage tissue formed $[5,12,13]$. The method adopted in the present study for confirming differentiation of MSC into chondrocytes was based on cell morphology by staining with Alcian Blue in low $\mathrm{pH}$. This technique stains the sulfated proteoglycans characteristic of cartilage matrix and has been used in a numerous earlier studies $[1,8,9]$.

\section{CONCLUSION}

These results confirmed the viability of devising a reliable, reproducible and consistent animal model for obtaining MSC. Of the several variables analysed, the best results were obtained from the inguinal region of rat.

Acknowledgments:We thank Lilian PiñeroEça, Flávia Coelho, Lia Mara Rossi for the laboratorial research support. Conflicts of Interest: The authors declare no conflict of interest.

\section{REFERENCES}

1. Zheng B,Cao B, Li G, Huard J. Mouse adipose-derived stem cells undergo multilineage differentiation in vitro but primarily osteogenic and chondrogenic differentiation in vivo. $J$ Tissue Eng.2006;12:1891-1901.

2. Choumerianou DM, Dimitrou H, Kalmanti M. Stemcell: promises versus limitations. Tissue Eng. Part B,Rev.2008;14:53-60.

3. Pelttari K, Steck E, Richter W. The use of mesenchymal stem cells for chondrogenesis. Injury2008; 39:S58-S65.

4. Mazzetti MP, Oliveira IS, Miranda-Ferreira R, Fauaz G, Ribeiro CN, Gomes PO, et al. Qualitative and quantitative analysis of rabbit's fat mesenchymal stem cells.Acta CirBras2010; 25:24-27.

5. Martínez-Lorenzo MJ, Royo-Cañas M, Alegre-Aguarón E, Desportes P, Castiella T, García-Alvarez F, et al. Phenotype and chondrogenic differentiation of mesenchymal cells from adipose tissue of different species. $J$ Orthop Res2009;27:1499-1507.

6. Arrigoni E, Lopa S, de Girolamo L, Stanco D, Brini AT. Isolation, characterization and osteogenic differentiation of adipose-derived stem cells: from small to large animal models. Cell Tissue Res2009;338:401-411.

7. Peptan IA, Hong L, Mao JJ. Comparison of osteogenic potentials of visceral and subcutaneous adipose-derived cells of rabbits. PlastReconstrSurg2006;117:1462-1470.

8. Frölich K, Scherzed A, Mlynski R, Technau A, Hagen R, Kleinsasser N, et al. Multipotent stromal cells for autologous cell therapy approaches in the guinea pig model. ORL J OtorhinolaryngolRelat Spec2011;73:9-16.

9. Eslaminejad MB , Mardpour S, Ebrahimi M. Mesenchymal stemcellsderived from ratepicardial versus epididymaladipose tissue. Iran J Basic Med Sci2011;14:25-34.

10. Suzuki T, Kobayashi K, Tada Y, Suzuki Y, Wada I, Nakamura T, et al. Regeneration of the trachea using a bioengineered scaffold with adipose-derived stem cells. Ann OtolRhinolLaryngol2008;117:453-463.

11. Kobayashi K, Suzuki T, Nomoto Y, Tada Y, Miyake M, Hazama A, et al. A tissue-engineered trachea derived from a framed collagen scaffold, gingival fibroblasts and adipose-derived stem cells. Biomaterials2010; 31:48554863.

12. Dominici M, Le Blanc K, Mueller I, Slaper-Cortenbach I, Marini FC, Krause DS, et al. Minimalcriteria for definingmultipotent mesenchymal stromal cells. The International Society for Cellular Therapy position statement Cytotherapy2006; 8:315-317. 
13. Im GI, Shin YW, Lee KB. Do adipose tissue-derived mesenchymal stem cells have the same osteogenic and chondrogenic potential as bone marrow-derived cells? Osteoarthritis Cartilage2005; 13:845-853.

14. Hennig T, Lorenz H, Thiel A, Goetzke K, Dickhut A. Geiger F, Richter W. Reduced chondrogenicpotential of adipose tissue derived stromal cells correlates with an altered TGFbeta receptor and BMP profile and is overcome by BMP-6. J Cell Physiol.2007; 211:682-691.

(C) 5 (5) 2020 by the authors. Submitted for possible open access publication under the terms and
conditions of the Creative Commons Attribution (CC BY NC) license
(https://creativecommons.org/licenses/by-nc/4.0/). 